\title{
JOGO NO RIO
}

\author{
Tamara Tania Cohen Egler \\ Fabiana Mabel De Oliveira
}

R E S U M O Como, por que e para quem são produzidas as politicas urbanas para os jogos esportivos na cidade do Rio de Janeiro? Os dados apresentados neste trabalho resultam de pesquisa realizada sobre os Jogos Pan-Americanos no Rio de Janeiro, em 2007. O artigo está estruturado em três eixos: discurso oficial; produção e apropriação social dos projetos; cidade democrática. No primeiro eixo, examinamos o que se veiculou como as benesses que os Jogos trariam para a cidade; no segundo, os projetos, a construção e a apropriação social dos equipamentos; e no terceiro, fazemos uma proposta de politica pública para o que designamos "uma cidade democrática". Este encaminhamento analítico tornou possivel observar, analisar e apresentar a distância que existe entre o discurso oficial e a realidade dos interesses que compuseram as estratégias para os jogos na cidade do Rio de Janeiro.

P A L A V R A S - C H A V E Globalização; politicas urbanas; grandes eventos esportivos; Jogos Pan-Americanos; redes; Rio de Janeiro.

\section{INTRODUÇÃO}

Quando o governo César Maia propôs a primeira candidatura do Rio de Janeiro para as Olimpíadas, em 1992, assistimos ao seu lançamento em Copacabana. Havia uma comemoração com ampla participação popular. Lá, pudemos observar caminhões, ao longo da orla, que distribuíam balōes de gás. Era possível perceber a lentidão das filas, compostas por muitas crianças, formadas próximo aos caminhões. Ao meio-dia, os balōes foram soltos, tomando os céus de Copacabana, e pensamos: "esta será a imagem-síntese da solidariedade carioca para a realização dos Jogos Olímpicos”. Assim lemos a primeira imagem do Rio para os Jogos Olímpicos. À noite, as emissoras de televisão do Brasil transmitiam para o mundo a imagem de uma solidariedade que não encontrava referência na realidade.

Esse é o ponto de inflexão que fez com que o nosso trabalho sobre a natureza do processo espacial progredisse. Tal ponto nos ajuda a perceber que, além de sua forma material e tangível, os processos de apropriação social são imateriais e intangíveis, e também nos revela que existe uma terceira dimensão do espaço, que se define por sua representação simbólica.

O debate está aberto e a questão teórica está colocada entre aqueles que acreditam que o capitalismo se perpetua, transvestido, e aqueles que examinam as transformações na ordem dos fatos, atores e processos que estão delineando uma nova complexidade que se realiza no entrelaçamento dos campos econômico e político, e que exigem uma orientação analítica alternativa que possibilite avançar na compreensão da realidade vivida.

Esse é o ponto de partida metodológico, que compreende a produção do conhecimento sociológico como representação da realidade (Morin, 2005). Como nos orienta Bourdieu (1998), a produção de conhecimento novo está associado à pesquisa dos que se propõem a observar os objetos, que fazem a unificação de categorias e conceitos que, reintroduzidos na realidade, são capazes de dar significado aos fatos, atores e processos observados, e, por fim, permitem a realização de procedimentos analíticos. 
Não se pode confundir mundialização com globalização. A mundialização é um processo histórico que estendeu as relações capitalistas para além das fronteiras nacionais - quando replicam nos Estados nacionais as experiências de produção dos países centrais. Nesse momento, centro e periferia se definem com clareza. Tais relaçôes se constituem por meio da produção de bens de produção e de consumo. As fábricas são construídas e as tecnologias são importadas para dar suporte ao desenvolvimento de uma sociedade mundial, para a reprodução de relaçães de produção e de apropriação capitalistas, em que se controla a produção, a circulação de mercadorias e de dinheiro. Nesse processo, identifica-se nitidamente a origem da corporação e das classes sociais. Assim, observam-se as categorias associadas aos modos de produção, circulação, troca e consumo, definidos por Marx (1978). As mercadorias têm um valor de uso e de troca, materialidade e apropriação social.

Nossa pesquisa revela as formas complexas de articulação entre atores, produção imaterial e expropriação social. Seus resultados revelam a centralidade da política urbana no contexto da globalização. No capitalismo mundializado, a política urbana produz mercadorias de natureza física e tangível; já na globalização, a mercadoria desaparece para dar lugar a um conjunto de negociaçóes interpretadas por diferentes atores que se articulam em rede e produzem um jogo para o desenvolvimento de negócios nunca antes imaginados.

Desse modo, pretendemos apresentar evidências empíricas e uma análise para representar a complexidade do negócio da expropriação que marca a política urbana das cidades globais.

Para participar da rede de cidades globais, o governo do Rio de Janeiro passou a realizar políticas urbanas capazes de colocar a nossa cidade na competitividade do sistema global. O que podemos observar é a formação de uma rede de corporaçóes dedicadas ao desenvolvimento de grandes eventos para a produção de atividades imateriais de forte conotação simbólica, nas quais os jogos esportivos, o turismo e os grandes projetos são apenas a ponta do iceberg.

Para avançar, é preciso compreender que os atores mudaram. Encontramos redes de corporaçōes globais que agregam grandes e pequenas empresas, governos de países ricos e pobres, agências de entretenimento, empresas aéreas, redes hoteleiras, distribuidoras de turismo, empresas de segurança, escritórios de arquitetura, capital imobiliário, organizaçôes sociais, e tantos outros. E todos atuando em benefício próprio, e de todos seus membros, ao mesmo tempo.

Ao dissecar as partes para entender o todo, é preciso descobrir o interior das redes globais, que se apresentam de forma invisível e altamente complexa. Elas têm peso e leis próprias, se constituem como unidades menores a compor as maiores por meio de suas inter-relações. O desafio é entender tais relações, nas quais existem estruturas e regularidades próprias, que fazem a cola entre as suas partes e que moldam e remodelam as redes capazes de fazer a coesão desses atores em beneficio de objetivos particulares e compartilhados.

Se a identificação dos atores é muito importante, não menos o são os objetivos em torno dos quais eles atuam. Mas é preciso ler um conjunto de estratégias que ampliam a mobilidade de pessoas em torno de cidades globais e em busca da satisfação de um desejo de consumo de bens imateriais associados ao entretenimento e à satisfação simbólica.

A sociedade de consumo de bens duráveis está esgotada. Vivemos em uma sociedade que consome bens não duráveis e intangíveis. Por isso a importância do turismo internacional, que faz mover milhóes de pessoas em torno do mundo e produz ganhos econômicos extraordinários. Para alavancar essa mobilidade, costuma-se realizar um grande evento - na 
área dos esportes, da cultura, da música, dos festivais de cinema, dos congressos científicos - capaz de concretizar a estrutura móvel da globalização. Pouco resta dos primórdios da fábrica e da vila operária; estamos diante de uma poderosíssima organização em rede, que defende atividades a serem realizadas nas cidades e que fazem parte do circuito global.

Nessa estratégia do processo de globalização, as cidades ocupam lugar de destaque: nelas se produzem outras necessidades que conduzem a novas subjetividades, as quais redefinem as relaçôes sociais, os corpos e as mentes. Isso, para fugir de uma abordagem meramente econômica, que subordina ao capital-dinheiro o capital político e social. Partindo dessa premissa, nos foi possível formular de forma geral a seguinte pergunta: como o processo de globalização transforma a política e a apropriação social do espaço urbano?

No desdobramento analítico foram enunciadas perguntas mais especificas: Qual é o discurso oficial? Quais são os atores e as estratégias de ação? De que forma podemos reconhecer os reais objetivos na produção dos projetos? Quem se beneficia? O que resta dos jogos para a cidade? Como se realizam os processos de expropriação? Como podemos construir uma cidade mais democrática?

Ressalte-se a importância dessa pesquisa na medida em que se aproxima a realização da Copa do Mundo e das Olimpíadas, no Rio de Janeiro e no Brasil, respectivamente. Daí a nossa responsabilidade intelectual e cidadã de revelar o que aconteceu com os Jogos Pan-Americanos, na esperança de que os resultados alcançados com a pesquisa acadêmica sejam socialmente apropriados.

\section{DISCURSO OFICIAL}

O discurso oficial está articulado a uma enunciação valorativa associada à inclusão da cidade do Rio de Janeiro no sistema de cidades globais. A política de realizar os Jogos Pan-Americanos na cidade é enunciada a partir da certeza de que o evento irá resultar num processo de multiplicação de outras atividades e gerar investimentos diretos e indiretos capazes de atrair investidores e de criar outras tantas atividades. Trata-se, portanto, de uma estratégia de ativação da economia, que tem por objetivo reverter o quadro de regressão econômica carioca. Compreende-se esse processo como uma grande oportunidade de transformar o Rio de Janeiro num palco privilegiado para a realização de grandes eventos.

Por ocasião da eleição da cidade do Rio de Janeiro para a realização dos Jogos Pan-Americanos, e de acordo com o Ministério do Esporte, seria necessária a quantia de $\mathrm{R}$ \$ 550 milhões. Desse total, cerca de R 310 milhões deveriam ser investidos pela Prefeitura, sendo esperado um retorno de até seis vezes este valor, quando o custo final ficou em torno de $\mathrm{R} \$ 3,7$ bilhōes. ${ }^{1}$

Nessa matriz econômica, a cidade passa a ser governada como um cenário para as atividades de turismo, um lugar que detém a infraestrutura necessária para receber extraordinário número de pessoas que irão gastar em moeda estrangeira e estimular as atividades econômicas locais. Esse processo seria responsável pelo desenvolvimento social. A produção de grandes obras estaria por conta de projetos-âncora para o desenvolvimento do turismo internacional. Nesse contexto, seria uma das atividades prioritárias de uma economia globalizada.

O projeto dos Pan-Americanos fez da cidade um grande palco para atrair essa multidão de turistas. O mega-projeto dos Jogos teve por objetivo transformar a urbe numa totalidade espacial, abrigando as mil atividades associadas à realização de eventos dessa
1 Conferir os dados em $<$ http://esportes.r7.com/ esportes-olimpicos/noticias/ legado-do-pan-foi-determinante-para-se-ganhar-a-olimpiada-20091002.html>. 
2 Jornal do Brasil. Rio de Janeiro, 18/1/2004. magnitude. Tratava-se de uma estratégia que tinha por objeto de produção o consumo de bens simbólicos, a beleza do corpo e a força do jogo. Uma totalidade de ação que transformaria a cidade em um palco; o corpo, em bem de consumo; e os sentimentos humanos, em objeto de apropriação. Essa política costuma se transformar num espaço importante quando é capaz de tornar a cidade um espaço da produção de bens simbólicos. O espaço urbano se transforma em cenário, capaz de produzir uma cena em que circulam atletas, médicos e turistas, atores dessa mega representação (Egler, 2007b).

Compreende-se que os resultados são muito importantes sobre o Produto Interno Bruto (PIB) de uma nação, no fluxo do turismo e de seus multiplicadores econômicos, chegando a se constituir, em economias avançadas, em uma máquina capaz de gerar em torno de $10 \%$ do PIB. Nessa lógica, a produção de um evento esportivo resulta em atividades econômicas que são ocasionadas pela estratégia de estímulo a eventos desse tipo. E se anuncia a criação de um milhão de empregos diretos e indiretos, como podemos ler em discurso de César Maia. ${ }^{2}$

Ao mesmo tempo, argumenta-se a favor da construção de equipamentos esportivos que deverão se constituir, após os jogos, no legado para a cidade e seus habitantes. A cidade carece de equipamentos esportivos, e o esporte é uma política pública para o bem-estar dos cidadãos. O discurso oficial afirma a importância de equipamentos esportivos para uso socialmente justo. Nosso objetivo, aqui, é responder à seguinte indagação: onde está a realidade desse discurso?

\section{A ESTRATÉGIA DE AÇÃO: PROJETOS E SUA APROPRIAÇÃO SOCIAL}

O processo de globalização deve ser percebido como um ininterrupto processo de difusão de um modo de pensar que valoriza o espaço simbólico e destrói o espaço real. Para pensar essas relações, Ribeiro \& Silva (2005) propõem uma visão à luz do conceito de impulsos globais como vetores que condensam informação e inovação associadas às novas formas de gestão. Essas formas estabelecem um modo de agir sistêmico por meio de tecnologias de informação e comunicação (TIC). Tais impulsos produzem novas formas de difusão das ideias que se propagam pelo mundo a uma alta velocidade e produzem novas formas de dominação. Criam vetores que se transmitem por partículas globais e movimentam todos os outros processos presentes no campo. Definem um novo processo de produção simbólica.

Para responder à pergunta “o que são sistemas simbólicos?”, Bourdieu (1998) orienta nossa análise quando dá como exemplos a linguagem, a arte, a religião - e podemos acrescentar a arquitetura. Trata-se de objetivar o sentido do mundo que se define pela concordância das subjetividades, que são estruturantes (senso = consenso), do indivíduo e do coletivo, quer dizer: estamos nos referindo a uma forma social coletiva da subjetividade. Os sistemas simbólicos são instrumentos do conhecimento e da comunicação; fazem a construção e a totalidade do mundo social. Seu poder é estruturante porque são organizados. Fazem a construção da realidade, e esta, por sua vez, tende a estabelecer uma ordem gnosiológica do sentido imediato do mundo e, em particular, do mundo social.

Os sistemas simbólicos definem novas estruturas de poder, já que produzem um discurso que faz a representação do mundo e de novas subjetividades, que transformam as práticas políticas. Aliam-se a isso os fundamentos de poder apontados por Hannah Arendt 
(1994), como o exercício da ação coletiva que resulta de uma percepção compartilhada do mundo social. A comunicação produz os fios invisíveis que a coesão social constrói em torno de objetivos compartilhados, estabelece o consenso do mundo e cria as possibilidades de ação coletiva em defesa de objetivos compartilhados. Na globalização, o poder simbólico se propaga pelo tecido social, por todas as naçóes e cidades; não é um poder centralmente localizado, mas junta todos na transversalidade dos campos, nações e escalas.

A propagação das ideias não tem fronteiras, e elas seguem vinculadas a impulsos que se concretizam em discursos e produzem uma atração: de governos, capitais e pessoas, ávidos em participar de eventos, sendo o objeto de dominação a vida social como um todo, em que o econômico, o político e o cultural se sobrepõem e se complementam (Ribeiro e Silva, 2005; Hardt e Nigri, 1999).

O processo de globalização tem outra forma específica de organização do poder. É uma rede que agrega atores econômicos, políticos e sociais de diferentes países do mundo. Não se identifica o seu comando; incorpora todos os atores dentro de uma ação que se expande rizomaticamente (Egler, 2009c). É uma complexa estratégia de ação para a formação da rede que reúne o governo federal, viabilizando o aporte de recursos financeiros; a prefeitura, que entra com as prerrogativas do Estado, o financiamento e a construção dos equipamentos e da infraestrutura; o capital privado nacional, que se responsabilizou pela construção dos grandes empreendimentos esportivos; e as pessoas comuns, com o trabalho voluntário!

A partir dessa estratégia, os atores se posicionam no campo. Vamos ver como esse jogo acontece na realidade: de que forma esse projeto transforma as condiçóes da existência social na cidade do Rio de Janeiro?

A realização dos Jogos Pan-Americanos teve um custo extremamente elevado. A previsão inicial foi de $\mathrm{R} \$$ 691.013.912. ${ }^{3}$ Hoje, esse valor subiu para cerca de $\mathrm{R} \$ 4$ bilhões. O custo médio das quatro edições anteriores (Santo Domingo, Winnipeg, Mar del Plata e Havana) ficou muito abaixo disso: $\mathrm{R} \$ 280$ milhôes cada. Em outras palavras, o Brasil gastou 14 vezes mais para produzir o mesmo evento, e a maior parte desse dinheiro - cerca de $90 \%$ - vem dos cofres públicos. ${ }^{4}$

Para avançar na investigação, a pesquisa de campo focou nos grandes empreendimentos destinados à realização dos jogos esportivos.

\section{QUEM GANHA E QUEM PERDE?}

Os atores que participam da rede global produzem estratégias alternativas de ação em defesa de interesses privados. Os Comitês Internacionais dedicados à realização de jogos movimentam milhões de dólares que beneficiam companhias de turismo e aéreas, redes hoteleiras, industrias de equipamentos esportivos, e os promotores dos jogos que arrecadam milhôes de dólares nas bilheterias. Trata-se de um mega-negócio que se realiza pela mediação de redes que atuam globalmente. Os comitês transvertem suas responsabilidades em nome da disputa dos jogos esportivos, para a representação da força e a comemoração entre as nações. É uma estratégia perversa, porque o dinheiro público é alocado na produção da infraestrutura dos jogos - o dinheiro gasto vem dos impostos pagos pela sociedade como um todo - e na produção simbólica de uma realidade inexistente, para que os lucros sejam realizados externamente pelos atores associados em rede, que participam da realização da grande festa. $\mathrm{Na}$ verdade, quem perde são os habitantes da cidade, que vêem
3 Conforme Diário Oficial, em 25 de novembro de 2005.

4 Disponivel em <http:// esportes.r7.com/esportes-olimpicos/noticias/ legado-do-pan-foi-determinante-para-se-ganhar-a-olimpiada-20091002>. <http:// www.anovademocracia.com. $\mathrm{br} /$ index2.php?option=com content\&do_pdf $=1$ \&id $=293>$. 
seus recursos aplicados de forma perversa e carente de justiça social. O campo da política urbana se arma de representações simbólicas para iludir, enganar, mentir e expropriar os interesses públicos.

\section{COMPLEXOS ESPORTIVOS}

A seguir apresentamos uma perspectiva do Rio onde podemos ler a localização dos grandes empreendimentos e um quadro em que estão indicados os resultados da pesquisa de campo que teve por objetivo identificar a destinação dos equipamentos, os atores responsáveis pelo financiamento e construção, custos econômicos, processo de gestão e formas de apropriação social. Com essas duas representaçôes, dedicadas a revelar produção econômica e apropriação social dos empreendimentos esportivos na cidade do Rio de Janeiro. Esse resultado da pesquisa de campo nos permite apresentar nossa análise.

Figura 1 - Localização dos empreendimentos esportivos

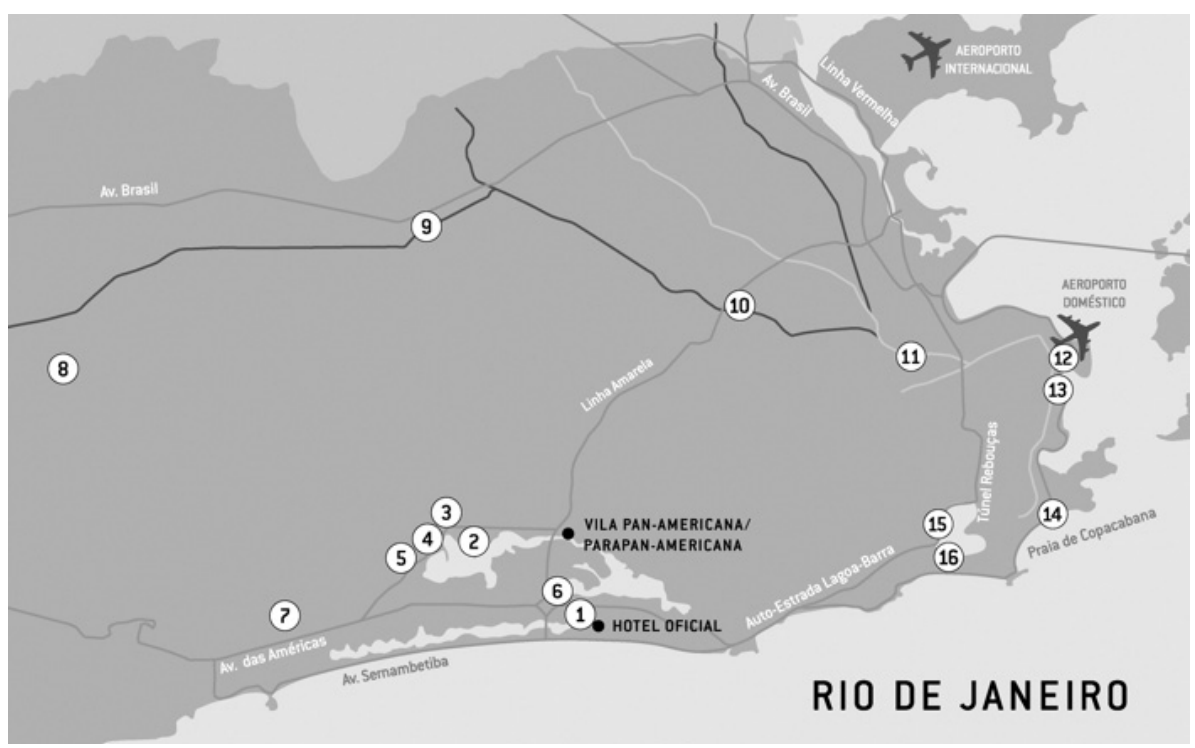

Fonte: Comitê Olímpico Brasileiro

1- Marapendi Country Club; 2- Complexo Cidade dos Esportes (Arena Multiuso, Parque Aquático Maria Lenk, Velódromo); 3- Morro do Outeiro; 4- Complexo Esportivo Riocentro; 5- Complexo Esportivo Cidade do Rock; 6- Centro de Boliche da Barra - Barra Bowling; 7- Centro de Futebol Zico; 8- Complexo Esportivo Miécimo da Silva; 9- Complexo Esportivo Deodoro; 10- Complexo Esportivo João Havelange (Engenhão); 11- Maracanã; 12- Marina da Glória; 13- Aterro (Parque do Flamengo); 14- Orla de Copacabana; 15- Lagoa; 16- Clube Caiçaras 
T A M A R A T. COH E N E L E R, FA B I A N A . D E O L I V E I R A

Quadro 1 - Complexos Esportivos para os Jogos Pan-Americanos - Produção Econômica e Apropriação Social

\begin{tabular}{|c|c|c|c|c|c|c|c|c|}
\hline Nome & Destinação & $\begin{array}{l}\text { Empresa } \\
\text { Construtora }\end{array}$ & $\begin{array}{l}\text { Agentes de } \\
\text { Financia- } \\
\text { mento }\end{array}$ & $\begin{array}{l}\text { Custo } \\
\text { em } \\
\text { milhões } \\
\text { de reais }\end{array}$ & $\begin{array}{l}\text { Natureza } \\
\text { do } \\
\text { equipa- } \\
\text { mento }\end{array}$ & $\begin{array}{l}\text { Capa- } \\
\text { cidade } \\
\text { de espec- } \\
\text { tadores }\end{array}$ & $\begin{array}{l}\text { Gestão } \\
\text { atual }\end{array}$ & $\begin{array}{l}\text { Uso } \\
\text { social } \\
\text { depois } \\
\text { dos } \\
\text { jogos }\end{array}$ \\
\hline Arena Multiuso & $\begin{array}{l}\text { Basquete e } \\
\text { ginástica artística }\end{array}$ & Rio Urbe & $\begin{array}{l}\text { Prefeitura do } \\
\text { Rio de Janeiro }\end{array}$ & 125.900 & Edificação & 15.000 & \begin{tabular}{|l|} 
Corporação \\
internacional \\
\end{tabular} & Não \\
\hline $\begin{array}{l}\text { Parque Aquático } \\
\text { Maria Lenk }\end{array}$ & $\begin{array}{l}\text { Natação, nado } \\
\text { sincronizado e } \\
\text { saltos ornamentais }\end{array}$ & Rio Urbe & $\begin{array}{l}\text { Prefeitura do } \\
\text { Rio e o Governo } \\
\text { Federal }\end{array}$ & 84.900 & Edificação & 8.000 & $\mathrm{COB}$ & Não \\
\hline Velódromo & $\begin{array}{l}\text { Ciclismo (pista), pa- } \\
\text { tinaçãa (velocidade) }\end{array}$ & Rio Urbe & $\begin{array}{l}\text { Prefeitura do } \\
\text { Rio e o Governo } \\
\text { Federal }\end{array}$ & 14.000 & Edificação & 1.500 & $\mathrm{COB}$ & Atletas \\
\hline Cidade do Rock & Beisebol e softbol & Rio Urbe & Prefeitura & 4.700 & $\begin{array}{l}\text { Instalação } \\
\text { temporária }\end{array}$ & 1.500 & Sem gestão & Não \\
\hline $\begin{array}{l}\text { Complexo } \\
\text { Esportivo } \\
\text { Riocentro }\end{array}$ & $\begin{array}{l}\text { Badminton, boxe, } \\
\text { esgrima, ginástica, } \\
\text { handebol, lutas em } \\
\text { geral, levantamento } \\
\text { de peso e tênis de } \\
\text { mesa }\end{array}$ & - & $\begin{array}{l}\text { GL Events e } \\
\text { Prefeitura }\end{array}$ & 35.000 & $\begin{array}{l}\text { Instalação } \\
\text { temporária }\end{array}$ & 4.500 & - & Cultura \\
\hline Barra Bowling & Boliche & - & Existente & Sem custo & $\begin{array}{l}\text { Instalação } \\
\text { temporária }\end{array}$ & 1.000 & Privada & Não \\
\hline Morro do Outeiro & $\begin{array}{l}\text { Ciclismo (Mountain } \\
\text { Bike e BMX) } \\
\end{array}$ & - & $\begin{array}{l}\text { Prefeitura do } \\
\text { Rio de Janeiro } \\
\end{array}$ & 2. 000 & $\begin{array}{l}\text { Instalação } \\
\text { temporária }\end{array}$ & 2.000 & - & Não \\
\hline $\begin{array}{l}\text { Complexo } \\
\text { Esportivo } \\
\text { Miécimo da } \\
\text { Silva (reforma) }\end{array}$ & $\begin{array}{l}\text { Patinação artística, } \\
\text { caratê, squash e } \\
\text { futebol }\end{array}$ & Rio Urbe & $\begin{array}{l}\text { Prefeitura do } \\
\text { Rio de Janeiro }\end{array}$ & 2. 400 & $\begin{array}{l}\text { Instalação } \\
\text { temporária }\end{array}$ & 4.000 & - & $\begin{array}{l}\text { Estudan- } \\
\text { tes }\end{array}$ \\
\hline Clube Marapendi & Tênis & - & $\begin{array}{l}\text { Prefeitura do } \\
\text { Rio de Janeiro }\end{array}$ & 5.100 & $\begin{array}{l}\text { Instalação } \\
\text { temporária }\end{array}$ & 5.750 & Privada & Não \\
\hline $\begin{array}{l}\text { Estádio de Remo } \\
\text { da Lagoa }\end{array}$ & $\begin{array}{l}\text { Canoagem de } \\
\text { velocidade, esqui } \\
\text { aquático e remo }\end{array}$ & $\begin{array}{l}\text { Glen Entertai- } \\
\text { ments. Ltda }\end{array}$ & $\begin{array}{l}\text { Estado do } \\
\text { Rio de Janeiro }\end{array}$ & 13.200 & Edificação & 3.000 & Prefeitura & Não \\
\hline $\begin{array}{l}\text { Orla de } \\
\text { Copacabana }\end{array}$ & $\begin{array}{l}\text { Maratonas } \\
\text { aquáticas, triatlo e } \\
\text { vôlei de praia }\end{array}$ & $\begin{array}{l}\text { Empresa } \\
\text { Orla Rio, } \\
\text { revitalização } \\
\text { de quiosques } \\
\end{array}$ & $\begin{array}{l}\text { Governo } \\
\text { Federal }\end{array}$ & 14.200 & $\begin{array}{l}\text { Instalação } \\
\text { temporária }\end{array}$ & & $\begin{array}{l}\text { Empresa } \\
\text { privada }\end{array}$ & Não \\
\hline $\begin{array}{l}\text { Complexo } \\
\text { Esportivo João } \\
\text { Havelange }\end{array}$ & Atletismo & - & $\begin{array}{l}\text { Prefeitura do } \\
\text { Rio de Janeiro }\end{array}$ & 408.600 & Edificação & 45.000 & $\begin{array}{l}\text { Clube } \\
\text { Botafogo }\end{array}$ & $\begin{array}{l}\text { Poucas } \\
\text { vezes }\end{array}$ \\
\hline $\begin{array}{l}\text { Maracanã } \\
\text { (reforma) }\end{array}$ & Futebol & $\begin{array}{l}\text { Governo } \\
\text { Federal e do } \\
\text { Estado }\end{array}$ & $\begin{array}{l}\text { Governo do } \\
\text { Estado e } \\
\text { Governo Federal }\end{array}$ & 245.000 & Edificação & 95.000 & $\begin{array}{l}\text { Governo do } \\
\text { Estado }\end{array}$ & Normal \\
\hline $\begin{array}{l}\text { Complexo } \\
\text { Esportivo } \\
\text { Deodoro }\end{array}$ & $\begin{array}{l}\text { Hipismo, hóquei } \\
\text { na grama, Pentatlo } \\
\text { Moderno (hipismo, } \\
\text { saltos, corrida e } \\
\text { tiro esportivo) } \\
\text { e tiro com arco } \\
\end{array}$ & $\begin{array}{l}\text { Construtora } \\
\text { Metropolitana } \\
\text { S/A }\end{array}$ & $\begin{array}{l}\text { Governo Federal, } \\
\text { Prefeitura e } \\
\text { Governo do } \\
\text { Estado do Rio de } \\
\text { Janeiro }\end{array}$ & 119.800 & Edificação & 7.000 & - & $\begin{array}{l}\text { Portadores } \\
\text { de } \\
\text { deficiência } \\
\text { física }\end{array}$ \\
\hline $\begin{array}{l}\text { Total das } \\
\text { instalações } \\
\text { temporárias }\end{array}$ & & & & 100.300 & & & & \\
\hline $\begin{array}{l}\text { Total de } \\
\text { edificaçôes }\end{array}$ & & & & 1.002 .200 & & & & \\
\hline Total & & & & 1.102 .500 & & & & \\
\hline
\end{tabular}

Fonte: Pesquisa de campo, elaborada pela estudante de Geografia e bolsista de IC Paula F. dos Santos.

A pesquisa de campo realizou o levantamento de 15 projetos para a realização de complexos esportivos. São três tipos de projetos: adaptação para instalaçóes temporárias, construção de uma nova obra, e reforma de obra já existente. 
O quadro nos revela importantes informações sobre a destinação da modalidade esportiva a ser desenvolvida nos empreendimentos, tais como ciclismo, natação, atletismo, patinação, futebol e vôlei.

Das 15 obras, sete foram realizadas por instalações temporárias - empresas internacionais vendem o projeto junto à obra. $\mathrm{O}$ argumento principal está associado à redução de custos para os governos. O processo se realiza da seguinte maneira: a empresa examina o local, cria o projeto e parte da utilização de elementos pré-moldados e desmontáveis. Depois da festa, o cenário é desmontado e suas peças transferidas para nova festa em algum lugar do mundo (cf. a entrevista de Christopher Lee, da Populus, empresa especializada em arquitetura e design de jogos olímpicos, em seminário do IAB, 27/05/2010).

Figura 2 - Ruínas do Complexo esportivo Cidade do Rock.

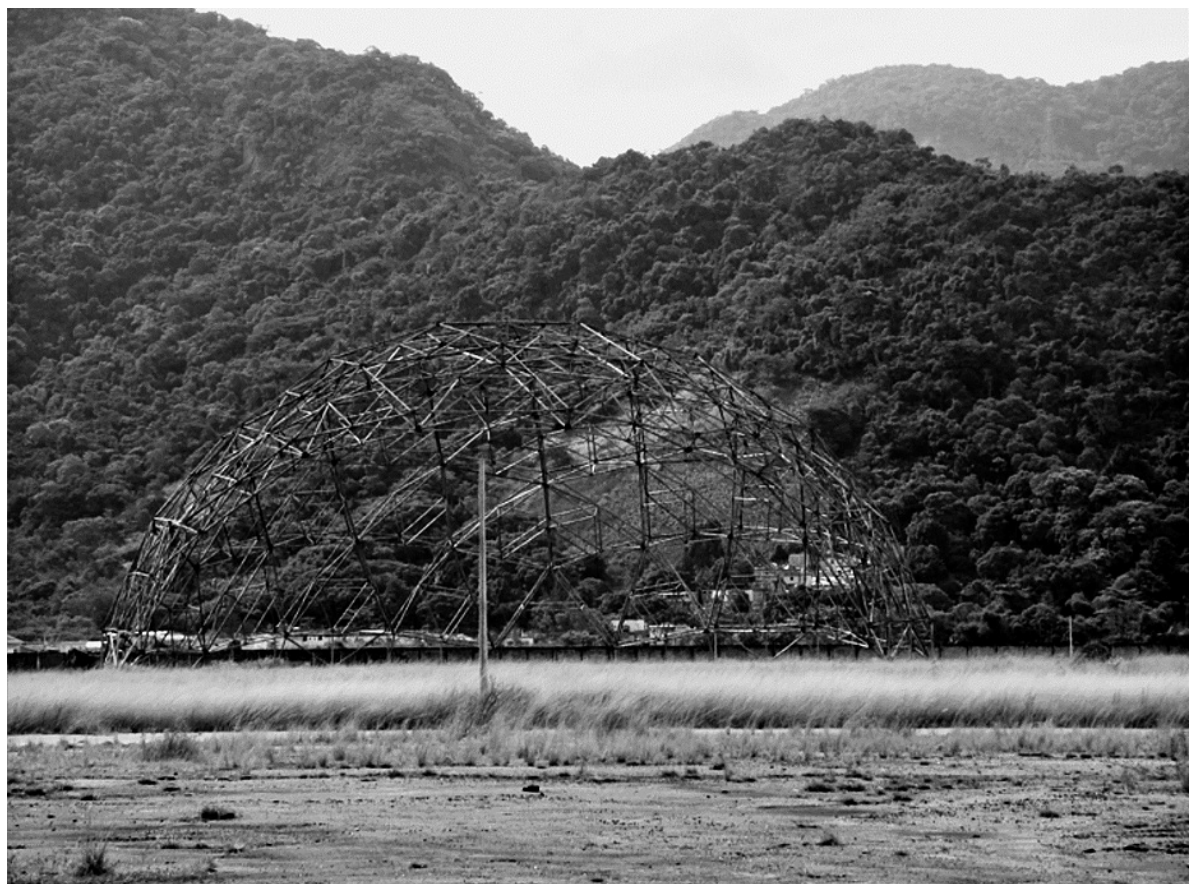

Fonte: Pesquisa de campo.

No que se refere ao processo econômico de produção dos empreendimentos, a Rio Urbe foi (e é) o principal ator, responsável pela construção das edificações vinculada à Secretaria de Obras da Prefeitura da Cidade do Rio de Janeiro; e é também a empresa do governo estadual do Rio de Janeiro. Foram contratadas duas firmas privadas para a construção de dois projetos. Na verdade, a grande maioria das firmas construtoras é de responsabilidade do setor público. O mesmo vale para os agentes de financiamento: na rede formada, os custos das instalaçôes são de responsabilidade dos governos brasileiros: poder público local, estadual e federal. Os custos econômicos com as instalaçóes temporárias somaram mais de cem milhões de reais; e com as edificaçôes permanentes,

6 Disponível em <http:// www.copa2014.org.br/noticias/3088/MP+PODE+REP $\mathrm{ETIR}+\mathrm{FIASCO}+\mathrm{DO}+\mathrm{PAN} 200$ 7+DIZEM+ESPECIALISTAS. $\mathrm{html}>$.
$\mathrm{R}$ \$ 1.002.200.000,00 (um bilhão, dois milhões e duzentos mil reais). Isso sem considerar que esses recursos se referem aos edifícios que foram examinados pela pesquisa e que não respondem pela totalidade dos gastos realizados, em torno de quatro bilhões de reais ${ }^{6}$ (Silva, 2010). 
Na última coluna da tabela podemos ler que depois da festa não foi possível observar a apropriação social dos equipamentos. O Engenhão foi arrendado para o Botafogo, e o Complexo Maria Lenk não permite o uso dos equipamentos, nem mesmo pelos nossos atletas consagrados nos Jogos. Nada resta para os habitantes da cidade. Os resultados da pesquisa, apresentados na tabela acima, revelam que em $80 \%$ dos casos os complexos esportivos são apropriados de forma privada, e que os atores da rede não permitem o uso social dos equipamentos.

Figura 3 - Estádio de Futebol João Havelange.

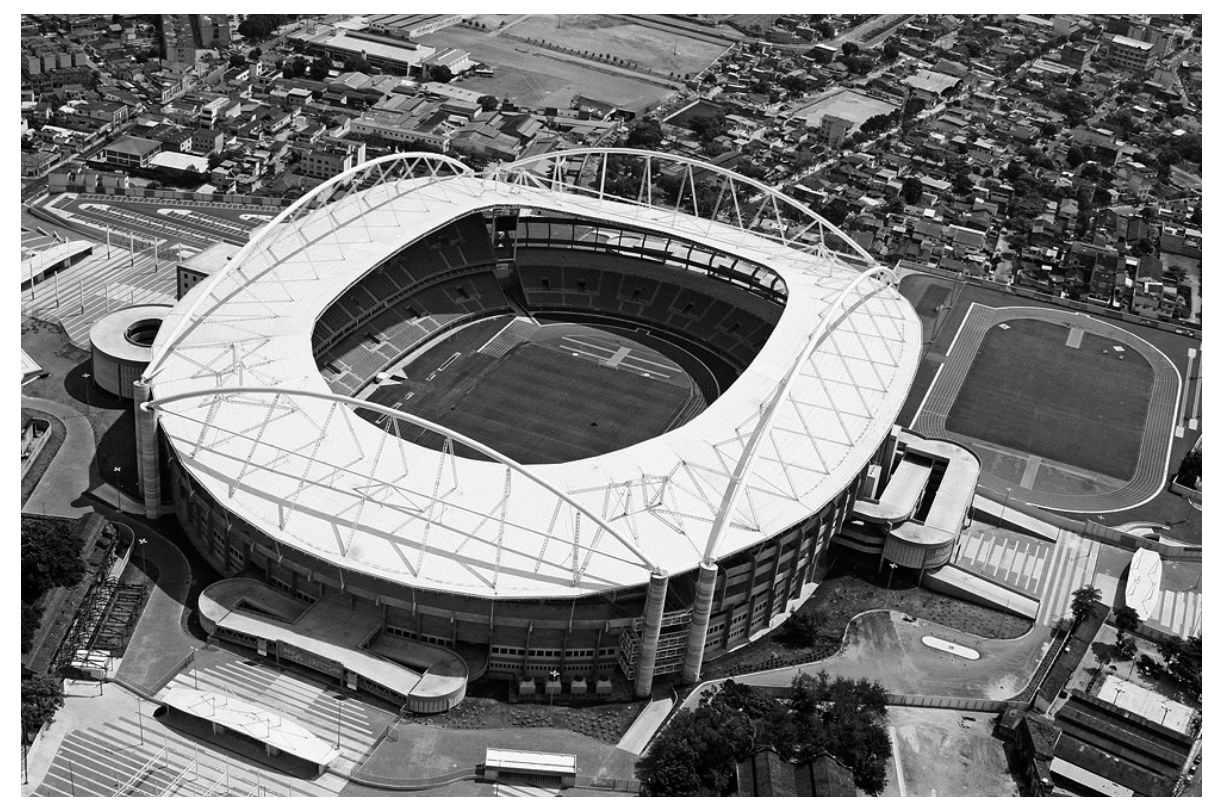

Fonte: Google Images.

Figura 4 - Parque Aquático Maria Lenk.

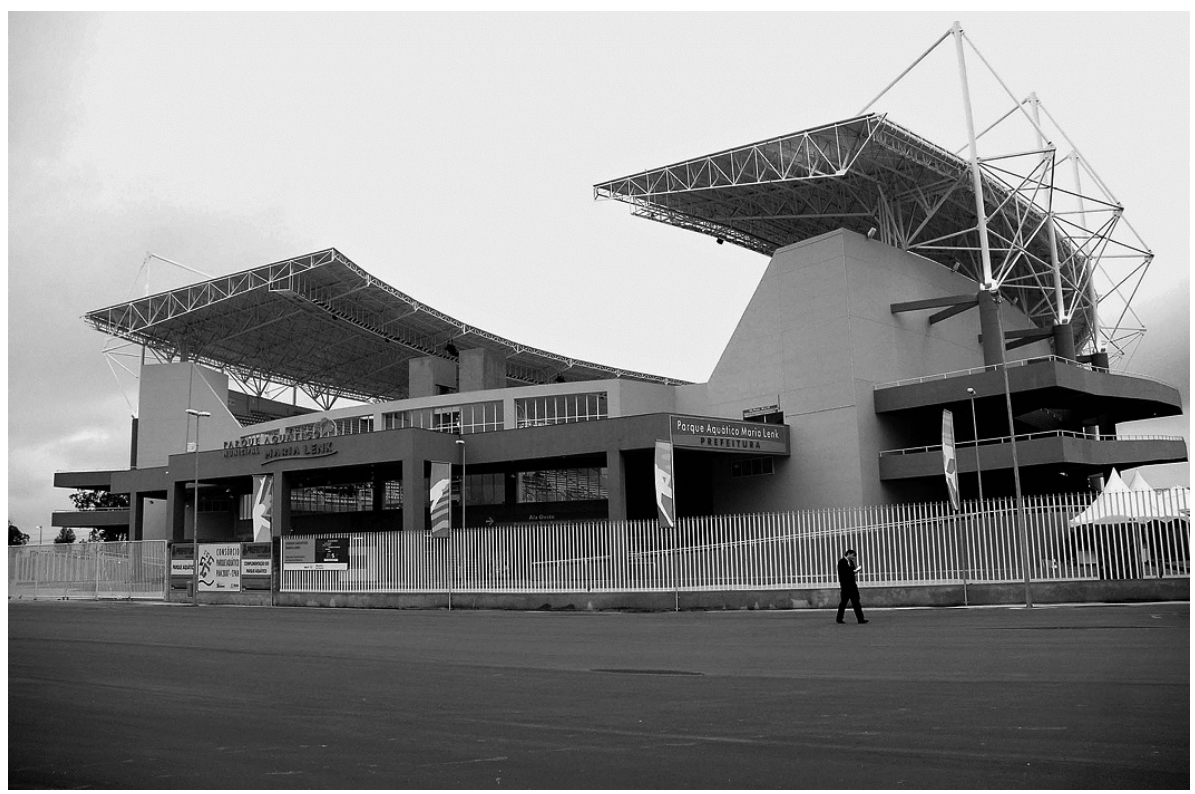

Fonte: Google Images. 
7 Disponivel em <http:// jbonline.terra.com.br/ pextra/2009/09/29/ e29099369.asp>.
Resta ainda registrar que processo acontece no Maracanã e no Riocentro, ambos reformados para os Jogos e importantes complexos da cidade, com tradição consolidada ao longo do processo histórico. Podemos considerar que se trata de uma apropriação socialmente justa no uso e ocupação dos seus espaços, enquanto construídos de fora para dentro, respondendo por uma ação material que destitui os sentidos do lugar. Mas isso é pouco diante dos desafios que observamos para o futuro de nossa cidade. ${ }^{7}$ É nosso objetivo avançar na pesquisa para examinar outros projetos e seus resultados para o alcance da justiça social. Isso para responder à pergunta: onde foram aplicados os 3 bilhões restantes?

Como podemos observar, a parceria é desequilibrada, o investimento para a construção dos empreendimentos é de responsabilidade do setor público carioca, e os ganhos são realizados pela rede de corporações globais. A infraestrutura é produzida localmente com recursos públicos pagos pela sociedade como um todo, mas os lucros são apropriados pelas empresas dedicadas às atividades de turismo, como as agências de viagem, redes de hotéis, operadoras de reservas, empresas aéreas e o Comitê Olímpico Brasileiro (COB) - estes constituem a rede de corporações atuante no mundo global. O dinheiro nem chega a entrar, porque é empenhado na compra dessa particular mercadoria intangível e simbólica, a participação no evento esportivo. Ele fica fora do país, uma vez que os pagamentos são intermediados por cartôes de crédito; e certamente é um grande negócio, por estar associado a uma economia intangível e simbólica, em que se monta um negócio invisível que pouco ou nada acrescenta às condições de vida numa cidade como a do Rio de Janeiro.

\section{A REDE DO JOGO}

Trata-se, portanto, da construção de um complexo sistema de atores em rede, e este tem por objeto constituir uma rede de cidades globais - conectando territórios por fluxos de tecnologias de informação e comunicação, constituindo uma espacialidade global, articulando diferentes escalas e esferas de ação que reúnem, sob um mesmo manto, interesses de corporações globais, de governos nacionais e capital imobiliário local. Poderíamos compará-lo à preparação de uma festa de aniversário. Mas quem utilizaria recursos próprios para mandar erguer o edifício da festa, convidaria pessoas que não conhece, faria um menu que lhe fosse estranho, serviria os convidados de forma subalterna, sem que tivesse o direto de sentar à mesa - mesmo depois da festa terminada?

É isso o que os nossos governantes fazem com a nossa cidade e seus cidadãos!

Apesar de o discurso prometer melhorias na condição da existência social dos moradores da cidade, nada resta. $\mathrm{O}$ discurso do legado cai por terra, a apropriação social não existe e fica uma ação que produz capital simbólico, cria a ilusão do bem-estar social e apropria sentidos, emoçóes e vida.

Senão, vejamos: o espaço simbólico é aqui compreendido como uma linguagem que representa o poder que as pessoas detêm sobre sua produção e apropriação. Todo espaço tem uma representação que hierarquiza a posição dos grupos sociais no espaço. Esse poder do espaço simbólico é resultado de um processo de representação que dignifica aqueles que têm o poder de se apropriar e estigmatiza aqueles que estão excluídos.

A novidade está no fato de que essa política urbana representa novas formas de expropriação e dominação. A cidade e seus cidadãos são transformados em objetos de 
interesses de fora. E isso nada tem a ver com a produção de mercadorias. Lembrando Marx (1978), a mercadoria está associada à produção de materialidades com valor de uso e de troca, e o ciclo de sua produção responde por um processo de produção, circulação, consumo e troca. O processo de acumulação resulta de uma relação de apropriação do trabalho alheio, que se realiza a partir do capital sobre o trabalho, se transforma em mais-valia e produz o ciclo de reprodução do capital e suas formas específicas de acumulação.

O processo que estamos examinando é muito mais complexo que a simples produção de mercadorias. Primeiro, porque não é um capital singular, mas uma rede que associa organizaçôes internacionais, corporações, governos e pessoas com interesses privados compartilhados. Segundo, porque não se produz nenhuma mercadoria; o que se vende é um capital simbólico para os turistas e moradores, quando se condensam promessas de felicidade pela participação em Jogos que representam a unificação de nações. E é cruel, porque se processa por meio de um discurso que convence milhares de pessoas e representa uma realidade que não existe.

É uma estratégia que delega às organizações internacionais, como é o Comitê Olímpico, a mediação de negociações em nome da paz mundial. E a partir de uma série de exigências, se produz um concurso mundial para abrigar grandes eventos globais. Para participar da festa global, os governos locais montam uma estratégia de grandes obras e arcam com os investimentos necessários. Ao final da festa, a máscara cai, e não sobra nada para turistas e moradores da cidade. Como podemos observar, é uma estratégia que se estrutura sobre a formação de uma rede que se move por uma ação que associa atores locais e globais em defesa dos interesses da rede. O que é muito diferente do papel dos atores e do ciclo de acumulação descritos por Marx.

No importante estudo de Steven Johnson (2003) sobre as teorias da auto-organização, cujo objeto de investigação são os fenômenos que associam os elementos com as partes, o ponto de partida de sua reflexão é o estudo do fungo Dictyostelium discoideum, que tem como característica a capacidade de existir de forma isolada e coletiva. Suas células se aglomeram e se separam de acordo com o contexto do mundo exterior: quando o ambiente é hostil, elas se separam; quando o ambiente é mais favorável, elas se unem para formar um único organismo.

Para avançar em nossa análise, é preciso examinar as relaçôes que se estabelecem entre aqueles que atribuem o poder aos "de cima" e os que o reconhecem nos "de baixo”. Os teóricos da mundialização e da manutenção da lógica capitalista reconhecem nas relações verticais e em suas lideranças a capacidade de produzir a expropriação. Esta hipótese, que considera necessária a liderança do capital para a realização do ganho econômico, reina até hoje, já que é muito difícil de se pensar em termos de uma ação que reúna capitais e governos.

Para entender o funcionamento das redes que fazem a defesa do interesse de fora, é necessário compreender a complexidade dos sistemas examinados. Neles é possível demonstrar que as estruturas se constituem por um processo que produz relaçóes que mesclam interesses de diferentes esferas e escalas. A pesquisa de Johnson (2003) sobre as redes revela um processo de exercício do poder que pode se manifestar de baixo para cima - ele o denomina de "emergência". A emergência está associada ao significado imanente da evolução dos sistemas; emergir é fazer aparecer o que está embaixo para ocupar uma posição em cima. Os resultados alcançados por seu estudo revelam como os comportamentos emergentes ficam mais inteligentes com o tempo e reagem de forma mais positiva às necessidades mutantes do seu ambiente (Johnson, 2003). 
Essa importante contribuição conduz nossa reflexão ao entendimento das leis da emergência no processo de produção e de apropriação do espaço urbano, no contexto da sociedade da informação e da comunicação globalizada - quando podemos identificar redes que mesclam interesses individuais e podem se constituir coletivamente de forma horizontal e cooperativa. São esses os fundamentos teóricos que sustentam nossa interpretação sobre a importância da comunicação, que intermedeia os indivíduos na formação de redes, os reúne em lugar comum, possibilitando o poder de expropriação coletiva. Todos os associados ganham no jogo, uns mais, outros menos.

No processo de expropriação que estamos estudando, as relações são mais complexas, vão além do valor de uso e de troca. Porque o objeto se constitui em uma representação que expressa o capital simbólico dos indivíduos participantes do sistema de cidades globais. Quando as cidades passam a ser lugar de prova e de consagração dos indivíduos que participam do seu sistema global, há uma forte hierarquia entre os indivíduos participantes e aqueles que não participam, determinando práticas sociais que expressam uma lógica geral do comportamento social dos indivíduos globais. Quer dizer: a separação entre capitalistas e trabalhadores não pode mais ser uma referência teórica, porque são novas as relaçóes sociais que explicam as diferenças entre os indivíduos que participam e os que não participam das comemorações globais. Mas esse processo não se esgota entre os indivíduos globais; ele perpassa todo o tecido social e penetra nos canais invisíveis da integração, plasmando a estrutura de valores da sociedade.

O espaço simbólico estabelece sentidos de superioridade social e moral, autopercepção e reconhecimento, que conduzem a práticas sociais inaugurantes de novas relações de inclusão e exclusão entre os grupos globalizados e não globalizados. Os grupos dominantes se autoatribuem a condição de pessoas com maior valor humano; e os outros grupos são considerados compostos de pessoas de menos valor humano - é construída uma barreira afetiva entre os grupos globais e os locais (Bauman, 1999).

Atualmente está em debate a realização da Copa do Mundo em 2014 e das Olimpíadas em 2016. Os projetos se centram na produção de uma infraestrutura de transportes capaz de articular os territórios renovados para os jogos. Para a Copa do Mundo de 2014 estão incluídas 59 obras, 12 delas em reformas de estádios. O custo total previsto é de $\mathrm{R} \$ 17,52$ bilhōes, incluindo verbas federais, estaduais e privadas.

A questão principal se estende entre sediar as atividades principais no centro da cidade ou na Barra da Tijuca, sendo os projetos de arquitetura e urbanismo propugnados e discutidos quanto à localização, custos econômicos e benefícios para a cidade e seus moradores.

As evidências empíricas apresentadas nos permitem demonstrar como é efêmera a produção do espaço simbólico, pois, depois da festa, a máscara cai e sobra uma grande dívida para as pessoas no que diz respeito à sua realidade social.

Trata-se, também, de um processo que gera o esgarçamento do tecido social e amplia a violência. Para alterar essa relação é preciso estabelecer limites ao processo de dominação e fazer políticas urbanas associadas ao desenvolvimento do espaço social em si, e não de sua representação simbólica, além de produzir um conhecimento que orienta a formulação de propostas alternativas de políticas urbanas, tendo por objetivo a equidade

8 Análise do professor Rainer Randolph apresentada no curso de doutorado (Ippur/UFRJ, 2007) sobre "Estado, planejamento e território". econômica, a liberdade política e a justiça social nas cidades. Compreendemos que isso só será possível com a mudança do sistema político. ${ }^{8}$

O que fazer para produzir uma cidade mais democrática? 


\section{REDE DO RIO}

Conhecemos os limites da democracia representativa. Quando Habermas (1990) propõe uma democracia radical, ele conhece os limites do sistema político atual e sugere novos caminhos para sua realização. Segundo o autor, o importante é a transformação do sistema político e não a mudança de partido. É preciso distinguir entre democracia liberal e democracia radical. A primeira é construída sobre pressupostos de participação de indivíduos em eleições. A segunda está estruturada sobre pressupostos de formação de coletivos em todas as esferas da vida cotidiana (Habermas, 2000). Existe uma grande diferença entre os fundamentos da democracia liberal e os da democracia radical. Enquanto a primeira delega o poder, a segunda reconhece a formação do poder pela ação coletiva, por dentro do tecido social. A democracia liberal é representativa e parte do indivíduo; o coletivo se define no mercado, sendo este uma categoria econômica. A democracia radical de Habermas parte do coletivo, é uma categoria política.

A comunicabilidade assegura "a vontade popular" como expressão da "vontade coletiva, quando cada um pode utilizar o mesmo sobre todos e todos sobre cada um" (Habermas, 1990). A questão está, portanto, associada à produção do espaço público no qual se propóe o exercício da vontade coletiva e uma sociedade organizada em forma de associação, em vez de mercado livre e de coerção. Trata-se de valorizar um sistema político que focalize a espontaneidade e a auto-organização social.

Mas como fazer isso?

O espaço público é mal compreendido; às vezes ele está associado às suas formas edificadas; outras vezes, aos processos eleitorais. O conceito de espaço público que utilizamos associa-se à comunicabilidade em geral, e ao seu papel na formação do tecido social. Para nós, é uma relação social que permite o compartilhamento de ideias, que possibilita a criação de um senso comum e conduz à formação de identidades; permite a coesão social e o exercício da ação política transformadora. Trata-se de entender o papel da comunicação na unificação dos indivíduos em sociedades.

Como foi possível perceber, na análise da Rede do Jogo, quanto maior a capacidade dos sistemas de se unificarem, maior é o poder de formar a opinião coletiva e a defesa de interesses compartilhados. É preciso perceber que estamos diante de formas alternativas de organização econômica e política, o que exige novas formas de resistência social. Por isso, nossa proposta é fazer avançar o pensamento para a importância da formação de um espaço público alternativo, que queira constituir uma rede do Rio, ou seja, uma rede social que se comunica em benefício da formação de um espaço público para a defesa das condições de vida e trabalho na cidade.

Por que o debate é importante?

Em geral, considera-se que o poder deve ser exercido pela máquina política, pelos especialistas e pelos burocratas. Nessa interpretação, os cidadãos não seriam capazes de exercer o governo; a vida de todos deveria ser racionalizada e gerida pelos mais preparados e habilitados técnica e politicamente. É quando se considera que o governo da sociedade é incompetente para decidir sobre o seu destino. Mais do que isso: como o bem comum significa coisas diferentes para pessoas diferentes, seria impossível reconhecer a vontade coletiva. Essa é a posição hegemônica.

A pergunta, então, é: quem são os atores da enunciação do discurso que forma a vontade coletiva? 
Enquanto o discurso da mídia é de um para todos, o discurso na Internet pode ser de todos para todos. Essa é a condição que move nossa proposta: produzir um discurso alternativo, mediado por tecnologias de informação e comunicação (TIC), que possa produzir uma nova interlocução, capaz de instigar uma vontade coletiva contra-hegemônica. Boaventura Souza Santos (2002) revela os caminhos da democracia participativa, compreendidas como prática cotidiana, como forma de aperfeiçoamento da convivência humana, de uma nova gramática de organização da sociedade e da relação entre Estado e sociedade, para toda organização econômica, política e cultural.

Pretende-se, portanto, valorizar a formação de coletivos em todas as esferas da vida social, quer seja na vida cultural, na economia e na política, e valorizar as referências solidárias e coletivas. Isso quer dizer que compreendemos, como alerta Bobbio (1978), que o exercício da democracia não é a participação de todos em todas as questôes. Os problemas da escola, do bairro, da cidade não são os mesmos que os da energia, dos transportes e do saneamento. Por isso, importa compreender que cada questão deve ser tratada por cada grupo que com ela se identifica. Dessa forma, os problemas de crianças deficientes são tratados pelos pais de crianças deficientes, que se associam em rede, com a participação de organizações governamentais e redes sociais. Assim, também, os problemas dos jogos na cidade do Rio de Janeiro podem e devem ser objeto de uma rede que se dedique à defesa da nossa cidade - para fazer frente aos efeitos das máquinas de controle da criatividade social.

Só nos resta contar com a importância da ação coletiva, orientada para a informação do que acontece na realidade em busca de objetivos coletivamente elaborados (Bourdieu, 1998). Para validar a vontade coletiva é preciso, primeiro, que exista a liberdade de opinião e difusão do conhecimento. É nesse lugar analítico que está posicionada a nossa resposta à pergunta "como fazer uma cidade mais democrática". A proposta é criar a Rede Rio, apta a promover a difusão da informação e do conhecimento e a ampliar o debate sobre a política urbana na cidade do Rio de Janeiro.

Propomos a formação de uma rede abrangendo um campo que produza a associação de diferentes atores, tendo por objeto de ação a defesa das condiçôes de existência social na cidade do Rio de Janeiro. A proposta objetiva criar uma rede de proteção que se proponha

Tamara Tania Cohen Egler é doutora em Sociologia (USP); professora do Instituto de Pesquisa e Planejamento Urbano e Regional (Ippur) da Universidade Federal do Rio de Janeiro (UFRJ); pesquisadora do CNPq; cientista do Nosso Estado da Faperj. E-mail: tamaraegler@ gmail.com

Fabiana Mabel de Oliveira é arquiteta; mestre em Artes e Tecnologia pela Universidade de Brasilia; bolsista de TCT da FAPERJ. E-mail: fabianamabel@ig.com.br

Artigo recebido em setembro de 2010 e aprovado para publicação em fevereiro de 2011. a realizar o acompanhamento e o reconhecimento dos principais atores que participam da concepção e realização dos programas e projetos de ação.

Essa rede deve ter como propósito, ainda, conectar, associar e articular a ação de laboratórios de pesquisa acadêmica, instituições governamentais, organizações da sociedade civil, empresas de capital privado e pessoas, a fim de estabelecer uma mediação entre os atores que tenham por objeto de ação as políticas urbanas para a realização da Copa do Mundo na cidade do Rio de Janeiro e das Olimpíadas em várias cidades brasileiras.

Daí a importância da ação coletiva orientada para a busca de objetivos elaborados de forma conjunta - seja em partidos políticos, associaçôes ou organizações da sociedade civil (Bourdieu, 1998b). Isto nos permitirá examinar como as tecnologias de comunicação e de informação podem ser utilizadas para formar redes que exercem a dominação na defesa de seus interesses particulares, e também para formar outras redes sociais, as quais, ao contrário, exercem a libertação na defesa de interesses coletivos. Precisamos inverter as relaçóes de dominação - no lugar das redes que dominam o jogo do Rio, redes que formem um coletivo para a defesa da vida na cidade do Rio de Janeiro. 
T A M A R A T. COH E E L L R, FA B I A A M. D E O L I V E I R A

\section{REFERÊNCIAS BIBLIOGRÁFICAS}

ARENDT, H. A dignidade da politica. Rio de Janeiro, Relumé du Mara, 1994.

BAUMAN, Z. Globalização: as consequências humanas. Rio de Janeiro: Jorge Zahar Editores, 1999.

BOBBIO, N. Quais alternativas para a democracia representativa? Marxismo e o Estado.

São Paulo: Graal, 1978.

BOURDIEU, P. O poder simbólico. Rio de Janeiro: Bertrand, 1998a.

. O neoliberalismo, utopia (em vias de realização) de uma exploração sem limites. Contrafogos, táticas para enfrentar a invasão neoliberal. Rio de Janeiro: Jorge Zahar, $1998 \mathrm{~b}$. EGLER, T. T. C. Políticas urbanas globais para espaços locais. Economia, Sociedade e Território, v. 5, n. 17, jan.-jun. 2005a.

. Jogos Pan-Americanos para um Rio global. In: VALENÇA, M. Globalização e marginalidade: transformaçôes urbanas. Natal: EDUFRN, $2007 \mathrm{~b}$.

- Virtual e vital nas redes de políticas urbanas. Comunicação apresentada ao III Simpósio Nacional Tecnologia e Sociedade, Curitiba, 2009c.

HABERMAS, J. Soberania popular como procedimento: um conceito normativo de espaço público. Novos Estudos Cebrap, São Paulo, n. 26, p.100-13, mar. 1990.

HARDT, M.; NEGRI, A. Império. Rio de Janeiro: Record, 2001.

JOHNSON, S. Emergência. A dinâmica das redes em formigas, cérebros, cidades e software. Rio de Janeiro: Jorge Zahar Editor, 2003.

MARX, K. El capital. Critica de la economía política. México: Fondo de Cultura Económica, 1978.

MORIN, E. $O$ método 3: O conhecimento do conhecimento. Trad. Juremir Machado. 3. ed. Porto Alegre: Sulina, 2005.

NORBERT, E. Os estabelecidos e os outsiders. Rio de Janeiro: Jorge Zahar, 2000.

RIBEIRO, A. C. T.; SANTOS, C. A. Impulsos globais e espaço urbano: sobre o novo economicismo. In: RIBEIRO, A. C. T. O rosto urbano da América Latina. Buenos Aires: Clacso, 2003. SANTOS, B. S.; AVRITZER, L. Para ampliar o cânone democrático. In: SANTOS, B. S. (Org.) Democratizar a democracia. Os caminhos da democracia participativa. Rio de Janeiro: Civilização Brasileira, 2002, p.39-82.

SILVA, P. F. O legado do Pan-Americano e a questão do uso social nos grandes empreendimentos. Comunicação apresentada no Encontro Nacional de Geografia, Florianópolis, 2010.

A B S T R A C T How, why and for whom are urban policies for sport games in Rio de Janeiro produced? The data presented here result from a research conducted on the Pan American Games held in Rio de Janeiro in 2007. The paper is divided in three axes: official discourse; production and social appropriation of the projects; democratic city. The first axis will examine what was reported as benefits that the Games would bring to the city; in the second, the projects, the construction and the social appropriation of the equipments; and in the third, we will make a public policy proposal for what we call "a democratic city". This analytical way allowed us to observe, analyze and present the gap between the official discourse and the interests that made up the strategies for the games in Rio de Janeiro.

K E Y W O R D S Globalization; urban policy; major events; Pan-American Games; Networks; Rio de Janeiro. 